\title{
Risk of well water pollution from the surface of a recharge area
}

\author{
J. Krivic \\ Geological Survey of Slovenia
}

\begin{abstract}
An aquifer acts as a pollution pathway between the source of pollution and the receptor. In this paper the risk of pollution of well water from a highway as the pollution source on a surface of a recharge area is estimated and discussed. A highway is a source of long-term pollutant release resulting from highway runoff and also the momentary release through spillage of hazardous materials. The solute transport through the individual segments of the system has been investigated in order to evaluate the probable pollutant concentrations in the well water. The study showed that the long-term low-level pollutant release presents almost no risk whereas the momentary releases of large quantities of hazardous liquids present a high risk to well water quality.

Keywords: wellhead protection area, highway runoff, groundwater pollution, solute transport.
\end{abstract}

\section{Introduction}

Groundwater is one of the most important sources of drinking water. Various activities in a recharge area of a groundwater pumping station pose a threat to the quantitative and qualitative state of well water and ground water in general. Furthermore, any activity on top of an aquifer or in its recharge area poses a threat to groundwater. The risk of well water pollution from such activities should be properly assessed. Consequently, measures should be taken in order to protect the groundwater bodies from pollution, with special emphasis being put on the protection of the recharge areas of existing wells. However, the flat surface of a typical lowland aquifer is predominantly used for agriculture and urbanization, and it is also particularly convenient for building transport infrastructure. These sorts of conflicts of interests can be resolved using risk 
assessment. Risk assessment can be used to achieve an optimal balance between different types of land use and protection of the environment. Different protective measures and restrictions can be applied in different areas according to the vulnerability of the environment. The protective measures and their influence on pollution risk mitigation should be validated through risk assessment.

Before risk can be assessed, hazards have to be identified and exposure has to be assessed. In environmental risk assessment the pollution source presents a hazard, pathways presents a route for exposure and well water presents an exposed subject or receptor. The receptor exposure depends upon several factors, such as climate, vegetation, soil type, geological setting, groundwater hydrology, and receptor characteristics. The aim of groundwater pollution risk assessment studies, where the pumping well is the receptor, is to predict the concentrations of pollutants in well water.

The exposure route or pathway is the aquifer between the pollution source and the receptor. The governing processes in the aquifer are: infiltration of water with dissolved pollutants, water flow in both unsaturated and saturated zone of the aquifer, solute transport processes in both unsaturated and saturated zone of the aquifer, and natural attenuation mechanisms. The transport processes are advection, i.e. bulk movement with groundwater flow, dispersion and diffusion. The natural attenuation consists of chemical reactions, biodegradation, and physical processes, such as dilution, volatilization and sorption.

The environmental risk assessment combines the knowledge of pollution source terms with the knowledge of the pollution pathway, i.e. the governing processes of pollution transport from the source to the receptor. The basis for the risk assessment of groundwater pollution should therefore be adequate hydrogeological and transport models.

\section{Aquifer as the exposure route}

An aquifer is usually composed of different segments with substantially different governing processes in water flow and solute transport. An aquifer can almost always be divided in at least two parts, if not more: an unsaturated zone, and a saturated zone, as shown in Fig. 1. The aquifer is either confined or unconfined. When covered by an impervious layer, the aquifer is confined. The impervious layer protects the aquifer from influences on the surface. When the aquifer is unconfined, it is not covered by a protective impervious layer, so pollution from the surface can easily reach the groundwater table.

All parts of an unconfined aquifer, from the source of pollution on the surface of the recharge area to the well, compose the pathway (Fig. 1) that has to be included in the risk estimation. Since parts of the pathway might be very different in dimension and characteristic processes, they are usually investigated separately. The partial results that are obtained are then combined in an integral risk estimate.

In the unsaturated zone of the aquifer the vertical water flow and solute transport prevail. Therefore, the area of interest in the unsaturated zone is usually 
not much larger than the area of the source of pollution. The unsaturated zone is typically not more than a couple of tens of metres thick. The modelling of water flow and solute transport in the unsaturated zone is usually best modelled using 1-D or 2-D finite-element numerical models.

In the saturated zone of the aquifer the subhorizontal water flow and solute transport prevail. The area of interest in the saturated zone can be several orders of magnitude larger than the dimensions of the area of interest in the unsaturated zone. 3-D finite-difference numerical models are usually used to model groundwater flow and solute transport in the saturated zone of the aquifer.

\section{Water flow and solute transport in porous media}

\subsection{Water flow in an unsaturated zone}

There are several approaches to describing the water flow in an unsaturated zone. One of the most commonly used is the Richards equation (Apul et al [1]). Its two-dimensional form is as follows:

$$
\frac{\partial \theta}{\partial t}=\frac{\partial}{\partial x}\left(K(h) \frac{\partial h}{\partial x}\right)+\frac{\partial}{\partial z}\left(K(h) \frac{\partial h}{\partial z}\right)+\frac{\partial K}{\partial z}
$$

where $\theta[-]$ is the volumetric water content, $h[\mathrm{~L}]$ is the pressure head, and $K$ $\left[\mathrm{LT}^{-1}\right]$ is the unsaturated hydraulic conductivity. The dependency of the water content $\theta$ on the soil matric potential $\psi_{\mathrm{m}}$ is defined by the soil water characteristic or soil water retention curve, $\theta\left(\psi_{\mathrm{m}}\right)$ (Mallants [2]). In addition to the knowledge of the soil water retention characteristics, $\theta\left(\psi_{\mathrm{m}}\right)$, the description of water movement in porous media also requires knowledge of the hydraulic conductivity function $K\left(\psi_{\mathrm{m}}\right)$.

The most widely used model for describing the soil water retention characteristics and the unsaturated hydraulic conductivity is by van Genuchten [3]. This model is based on the statistical pore size distribution model of Mualem $[4]$.

\subsection{Water flow in a saturated zone}

Water flow in saturated media is governed by Darcy's law (Mallants [2]). For the isotropic media, this equation can be written as follows:

$$
v=K \cdot i ; \quad i=\frac{d h}{d s}
$$

where $v$ is the water flow velocity $\left[\mathrm{LT}^{-1}\right], i$ is the hydraulic gradient [-], $K$ is the hydraulic conductivity $\left[\mathrm{LT}^{-1}\right], h$ is the total potential or hydraulic head [L], and $s$ is the flow path [L]. 
The general flow equation in a porous media is given by the combination of Darcy's law and the principle of mass conservation. It can be solved with standard numerical methods for a one-, two-, or three-dimensional domain of complex geometry. Its most simple form is obtained when the medium is isotropic and steady state flow is reached.

\subsection{Solute transport}

Solute transport in a porous medium depends on various phenomena. It can be described by the following equation, Eqn (3) (Zheng and Wang [5]), applicable for the three-dimensional transport of dissolved substances in groundwater (if reactions are limited to sorption and first-order decay):

$$
\frac{\partial C}{\partial t}=-\underbrace{\frac{\partial}{\partial x_{i}}\left(v_{i} C\right)}_{\text {advection term }}+\underbrace{\frac{\partial}{\partial x_{i}}\left(D_{i j} \frac{\partial C}{\partial x_{j}}\right)}_{\text {dispersion term }}+\underbrace{\frac{q_{s}}{n_{e}} C_{s s}}_{\begin{array}{c}
\text { sources/sinks } \\
\text { term }
\end{array}}+\underbrace{\frac{\rho_{b}}{n_{e}} \frac{\partial C_{s}}{\partial t}-\lambda\left(C+\frac{\rho_{b}}{n_{e}} C_{s}\right)}_{\begin{array}{c}
\text { reaction term } \\
\text { (sorption and first order decay) }
\end{array}}
$$

where $C$ is the concentration of the dissolved substance $\left[\mathrm{ML}^{-3}\right], x_{i}$ is the distance along $\mathrm{i}$ axis $[\mathrm{L}], v_{i}$ is the pore velocity $\left[\mathrm{LT}^{-1}\right], D_{i j}$ is the hydrodynamic dispersion tensor $\left[\mathrm{L}^{2} \mathrm{~T}^{-1}\right], q_{s}$ is the sources/sinks volumetric flux of water per unit volume of aquifer $\left[\mathrm{T}^{-1}\right], n_{e}$ is the effective porosity $[-], C_{s s}$ is the concentration of the sources/sinks $\left[\mathrm{ML}^{-3}\right], \rho_{b}$ is the bulk density of the porous medium $\left[\mathrm{ML}^{-3}\right], C_{s}$ is the concentration of the substance sorbed on the porous medium [-], and $\lambda$ is the rate constant of the first-order reaction or decay constant $\left[\mathrm{T}^{-1}\right]$.

\section{Simulating water flow and solute transport}

In order to adequately represent the complex geometry of an unsaturated zone or to simulate some specific phenomena, such as capillary barrier, the Richards equation, Eqn (1), is solved numerically. The numerical simulations of water flow and solute transport in the unsaturated zone in the presented study were carried out using the finite-element water flow and solute transport code Hydrus2D (Šimůnek et al [6]).

For the modelling of water flow and solute transport through the saturated zone of the aquifer the three-dimensional Groundwater Modelling System (GMS) v5.1 from Brigham Young University [7] was used. Within the user interface of GMS, several computer codes are linked. Flow simulations were done with MODFLOW-2000 code (Harbaugh et al [8]), particle tracking with MODPATH (Pollock [9]) and transport simulations with the MT3DMS code (Zheng and Wang [5]). The MODPATH code uses the output from flow simulations obtained with MODFLOW to compute three-dimensional flow paths. 


\section{Case study}

In this study, the possibility of pollution in a recharge area, which would influence well water quality, was investigated.

In the first step of the study the adequacy of the existing wellhead protection area was evaluated. A regional hydrogeological model of the saturated zone of the entire aquifer was built for that purpose. Inverse particle tracking from the extraction wells was performed in order to define the recharge area of the wells. Particle tracking models calculate the flow paths, which are the advective paths of fictitious particles released at a certain point in the system. Flow paths are based on the results of a flow model. They give an idea about the travel time and the area influenced by the release of a pollutant. However, they only give qualitative results because they do not take into account all phenomena involved in the transport of a pollutant in a porous media (for instance, processes such as hydrodynamic dispersion, sorption, and decay). On the basis of particle tracking all of the recharge area was found to be within the wellhead protection area, which was therefore evaluated as appropriately defined.

Some existing and some planned objects were identified as potential sources of pollution in the wellhead protection area. The planned objects, which were identified as potential sources, are connected with the construction of a new highway across the recharge area of the wells. The highway itself presents a linear source of numerous pollutants whereas different objects along the highway, such as gas station, maintenance base, and toll house, present point sources of pollutants. In the investigated recharge area a highway maintenance base is planned.

Normal highway traffic causes long-term pollutant release. Pollutants originating from usual highway traffic include various heavy metals, lubricants, fuels, hydraulic liquids, coolants, nutrients, and other organic and inorganic substances (Apul et al [1]). Unusual critical events, such as a road tanker accident, can result in the spillage of large quantities of various hazardous liquids, which cause momentary releases of extreme quantities of pollutants.

In this study, a number of runoff sampling points were set up along highways, which have similar traffic characteristics to the expected traffic along the planned highway. The expected daily traffic is approximately 20,000 vehicles. The summary of the concentration ranges of some of the analysed chemicals is presented in Table 1 . The collected data on the concentration of chemicals of concern in highway runoff was used as an input in the model of the unsaturated zone of the aquifer. Additionally, different scenarios depicting the spillage of hazardous liquids were modelled. The worst case scenario incorporated the spill and infiltration of the total volume of a road tanker, i.e. $34.000 \mathrm{~m}^{3}$, transporting a highly mobile hazardous liquid. The liquid was treated as a conservative tracer, i.e. non-retarded and non-decaying.

\subsection{Modelling the unsaturated zone}

The water flow and solute transport in an unsaturated zone were simulated in a 2-D vertical cross-section, which is indicated in fig. 1. 
Table 1: Concentration of selected chemicals in highway runoff.

\begin{tabular}{|c|c|}
\hline Chemical of concern & Concentration [mg/l] \\
\hline $\mathrm{Pb}$ & $0,0003-0,017$ \\
\hline $\mathrm{Zn}$ & $0,0115-0,1188$ \\
\hline $\mathrm{Cd}$ & $0,00006-0,001$ \\
\hline $\mathrm{Cu}$ & $0,012-0,025$ \\
\hline $\mathrm{Ni}$ & $0,0002-0,0004$ \\
\hline $\mathrm{Fe}$ & $0,014-2,1$ \\
\hline $\mathrm{Cr}{ }_{\text {tot }}$ & $0,0019-0,0064$ \\
\hline $\mathrm{N}$ & $3,96-7,48$ \\
\hline $\mathrm{P}$ & $0,021-0,027$ \\
\hline $\mathrm{K}$ & $1-460$ \\
\hline $\mathrm{CN}^{-}$ & $0,01-0,02$ \\
\hline $\mathrm{Cl}^{-}$ & $6,6-4400$ \\
\hline
\end{tabular}

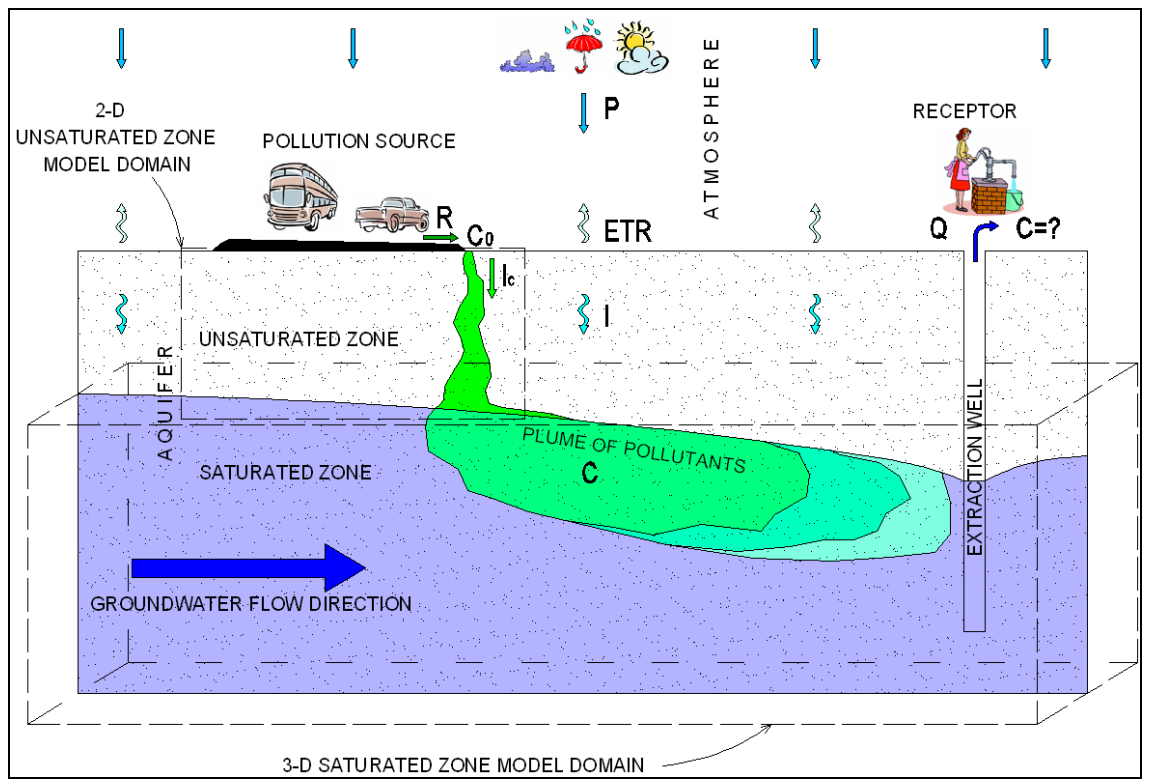

Figure 1: Migration of pollutants through aquifer from source to receptor.

Vertically the 2-D model extended from the surface to the water table. The thickness of the model domain is approximately 12 meters. The unsaturated zone consists of highly pervious quaternary sandy gravel, which is covered by a humus layer.

The top boundary of the model represented atmospheric influences, such as precipitation and evapotranspiration, whereas the bottom boundary and the 
lowest parts of the vertical boundaries represented the groundwater table. The resulting time series of solute transport from the unsaturated zone to the groundwater was used as an input into the local model of the saturated zone of the aquifer.

\subsection{Modelling the saturated zone}

A local model of the saturated zone of the aquifer was built on the basis of the regional model. The modelled area of interest included the pathway from the source of pollution to the groundwater extraction wells, as illustrated in Fig 1. The distance from the source to the receptor was approximately 1200 meters. The saturated zone of the aquifer consists of quaternary sand gravel with hydraulic conductivity in the range of $10^{-3} \mathrm{~m} / \mathrm{s}$. The hydraulic gradient along the pathway is around 0.002 .

With the local hydraulic and transport model time series of concentrations of chemicals of concern in the wells were calculated on the basis of input from the model of unsaturated zone. The resulting concentrations were compared to threshold values in drinking water standards.

\section{Results of numerical modelling}

The results of the numerical modelling of solute transport through the unsaturated zone show that, with the transport parameters within the expected ranges, the majority of the chemicals of concern, which originate from long-term pollutant release, will not reach the groundwater table in a significant quantity within 100 years. Only the highly mobile chemicals, such as chlorides and nitrates, will reach the groundwater in high enough concentrations to pose a serious threat to groundwater quality. However, the momentary releases of large quantities of pollutants caused by critical events will almost certainly result in serious groundwater pollution.

The solute transport through the saturated zone of the aquifer results in further mitigation of the pollutant concentrations in groundwater. Therefore only the highly mobile chemicals of the long-term pollutant release are expected to reach the wells in detectable concentrations, Table 2.

Table 2: Maximum concentrations of highly mobile chemicals in well water.

\begin{tabular}{|l|c|c|}
\hline & $\begin{array}{c}\text { Max. concentration at the } \\
\text { source }[\mathbf{m g} / \mathbf{l}]\end{array}$ & $\begin{array}{c}\text { Max. concentration in the well water } \\
{[\mathbf{m g} / \mathbf{l}]}\end{array}$ \\
\hline $\mathrm{N}$ & 7.4800 & $1.42 \mathrm{E}-02$ \\
\hline $\mathrm{Cl}$ & 4400 & $8.35 \mathrm{E}+00$ \\
\hline
\end{tabular}

None of the chemicals of concern are expected to exceed or even be within the order of magnitude of the drinking water standards threshold values. On the other hand, pollutants originating from critical events pose a significant risk to the well water. Some of the modelled scenarios resulted in concentrations of 
chemicals of concern in groundwater exceeding the drinking water standards threshold values. In most critical cases, the calculated values were a couple of orders of magnitude above the allowed concentrations for various chemicals. The calculated concentration of the conservative tracer reached almost $30 \mathrm{mg} / \mathrm{l}$.

\section{Conclusions}

This study has shown that in the case discussed, the normal traffic along the highway across the well recharge area presents almost no risk to well water quality, although major spills of transported hazardous liquids present a serious risk to the well water quality.

In order to prevent pollutants from entering the aquifer, appropriate protective measures should be applied, especially in wellhead protection areas, where special emphasis should be put on the prevention of spillage of transported hazardous liquids.

Further studies regarding solute transport parameter characterization and pollutant source terms should be carried out in order to improve the reliability and precision of the results of the calculations. This way the presented semigeneric study would advance to a more realistic representation of the investigated environment.

\section{References}

[1] Apul, D.S., Gardner, K.H., Eighmy, T.T., Brannaka, L., Benoit, J., A Review of Water Movement in the Highway Environment: Implications for the Recycled Materials Use. Beneficial Use of Recycled Materials in Transportation Applications, ed. T.T.Eighmy, Air and Waste Management Association Press, pp. 195 - 204, 2003.

[2] Mallants, D., Basic concepts of water flow, solute transport, and heat flow in soils and sediments. SCK-CEN, Mol, Belgium, 2004.

[3] van Genuchten, M.Th., A closed-form equation for predicting the hydraulic conductivity of unsaturated soils. Soil Sciences Society of America Journal, 44, pp. 892 - 898, 1980.

[4] Mualem, Y., A new model for predicting the hydraulic conductivity of unsaturated porous media. Water Resources Research, 12, pp. 513-522, 1976.

[5] Zheng, C., Wang, P.P., MT3DMS: A Modular Three-Dimensional Multispecies Transport Model for Simulation of Advection, Dispersion, and Chemical Reactions of Contaminants in Groundwater Systems; Documentation and User's Guide, US Army Corps of Engineers, Washington, DC, 1999.

[6] Šimůnek, J., Šejna, M. \& van Genuchten, M.Th., The HYDRUS-2D Software package for Simulating the Two-Dimensional Movement of Water, Heat, and Multiple Solutes in Variably-Saturated Media, version 2.0, U.S. Salinity Laboratory, Riverside, California, 1999. 
[7] Brigham Young University, Groundwater Modeling System, GMS v5.1, Reference Manual, Environmental Modeling Research Laboratory, Brigham Young University, Utah, 2004.

[8] Harbaugh, A.W., Banata, E.R., Hill, M.C., McDonald, M.G., Modflow2000, User guide to modularization concepts and the ground-water flow process, United States Geological Survey, 2000.

[9] Pollock, D.W., User's Guide for MODPATH/MODPATH-PLOT, Version 3: A particle tracking post-processing package for MODFLOW, United States Geological Survey, Reston, 1994. 